\title{
THE TEXTS OF REGIONAL ORTHODOX MASS MEDIA: LINGUOSTYLISTIC ASPECT
}

\author{
Elena A. Ovechkina \\ Volgograd State University, Volgograd, Russia
}

\begin{abstract}
The paper deals with lexical, morphological and stylistic features of the texts of Orthodox print publications of the Volgograd diocese. It is revealed that along with the neutral book lexicon, the stylistically marked lexemes of the thematic group "Orthodox sacred and liturgical lexicon" are used in the texts. They are divided into four subgroups of words: 1) words denoting the basic notions of religion and theological terms; 2) words related to ritual and naming of the elements of worship; 3 ) words denoting the names of the Church hierarchy; 4) words denoting the names of the God and the Holy Virgin. The Orthodox sacred and liturgical vocabulary is represented by nouns, adjectives, verbs and adverbs. Church Slavonic words are used to create a solemn tone and to effect the reader. The morphological structure of the texts of Orthodox publications is predominantly nominal. The specificity of the studied texts is manifested in the use of present tense verbs of theological generalization, as well as imperative verbs. The syntactic peculiarity consists in the use of interrogative constructions, question-and-answer unities, positional-lexical repetitions, homogeneous elements of the sentence, inversions. The wide use of stylistic figures (anadiplosis, antithesis, gradation) in the texts is conditioned by the urge to focus attention on semantically meaningful fragments, as well as to enhance an expressive effect.
\end{abstract}

Key words: regional Orthodox edition, sacred and liturgical vocabulary, repetition, inversion, stylistic figure, mass media, stylistics.

Citation. Ovechkina E.A. The Texts of Regional Orthodox Mass Media: Linguostylistic Aspect. Vestnik Volgogradskogo gosudarstvennogo universiteta. Seriya 2, Yazykoznanie [Science Journal of Volgograd State University. Linguistics], 2018, vol. 17, no. 1, pp. 37-43. (in Russian). DOI: https://doi.org/10.15688/jvolsu2.2018.1.4

\section{ТЕКСТЫ РЕГИОНАЛЬНЫХ ПРАВОСЛАВНЫХ СМИ В ЛИНГВОСТИЛИСТИЧЕСКОМ АСПЕКТЕ}

\author{
Елена Алексеевна Овечкина \\ Волгоградский государственный университет, г. Волгоград, Россия
}

\begin{abstract}
Аннотация. В статье выявляются лингвостилистические черты текстов православных печатных изданий Волгоградской епархии: дана их лексическая, морфологическая, синтаксическая и стилистическая характеристика. Установлено, что наряду с нейтральной книжной лексикой в текстах используются стилистически маркированные лексемы тематической группы «Православная сакрально-богослужебная лексика», входя$\infty$ щие в одну из четырех подгрупп: 1) слова, обозначающие основные понятия вероисповедания и богословс궁 кие термины; 2) слова, связанные с ритуалом и называющие элементы богослужения; 3) слова, обозначаю¿ щие названия церковной иерархии; 4) слова, обозначающие именования Господа и Богородицы. Православная сакрально-богослужебная лексика представлена именами существительными, прилагательными, глаголами и наречиями. С целью создания торжественного тона и воздействия на читателя используются церковнославянизмы. Морфологический строй текстов православных изданий имеет преимущественно именной §ิ характер. Специфика исследуемых текстов проявляется в употреблении в них глаголов настоящего времени () богословского обобщения, а также глаголов в повелительном наклонении. Синтаксические особенности
\end{abstract}


обусловлены использованием вопросительных конструкций, вопросно-ответных единств, позиционно-лексических повторов, однородных членов предложения, инверсий. Широкое употребление в текстах стилистических фигур (анадиплозиса, антитезы, градации) обусловлено стремлением авторов текстов акцентировать внимание на семантически значимых фрагментах, а также усилить выразительный эффект.

Ключевые слова: региональное православное издание, сакрально-богослужебная лексика, повтор, инверсия, стилистическая фигура, СМИ, стилистика.

Цитирование. Овечкина Е. А. Тексты региональных православных СМИ в лингвостилистическом аспекте // Вестник Волгоградского государственного университета. Серия 2, Языкознание. - 2018. - Т. 17, № 1. - С. $37-43$. DOI: https://doi.org/10.15688/jvolsu2.2018.1.4

\section{Введение}

Рост интереса социума к событиям церковной жизни, к православной культуре повлиял на то, что в современном медиапространстве все чаще звучит тема православия, расширяется спектр православных печатных изданий («Журнал Московской Патриархии», «Альфа и Омега», «Вода живая», «Наследник», «Православное слово», «Фома», «Христианское чтение» и др.); создаются православные радиостанции («Радио Вера», «Радонеж», «Воскресение», «Благовестие», «Град Петров», «Православное радио» и др.); телевизионные каналы («Союз», «Спас») и интернет-сайты (www.pravoslavie.ru, www.pravmir.ru, www.patriarchia.ru и др.). По мнению исследователей, на сегодняшний день православной журналистике удалось сформировать свою систему СМИ, которую можно отнести к особой типологической группе российских массмедиа. Появление большого количества православных печатных изданий обусловило развитие религиозно ориентированной светской журналистики (публицистики), предоставляющей информацию о религиозной жизни и дающей ее анализ, и формирование конфессиональной журналистики, распространяющей религиозное учение (проповедь в широком смысле этого слова) в рамках той или иной конфессии [Ицкович, 2011 с. 45]. Исследователи отмечают, что светская религиозная журналистика не зависит от религиозных организаций и может критично выражать собственное мнение, в отличие от конфессиональной журналистики, которая, «занимаясь распространением учения, проповедью, добровольно накладывает на себя определенные цензурные ограничения (жанровые, стилистические, тематические)» [Ицкович, 2011, с. 45].

Несмотря на широкий интерес к православной журналистике как со стороны общественности, так и со стороны научного сооб- щества, работ, посвященных изучению православных средств массовой информации, немного. Ученые акцентируют свое внимание на истории церковной журналистики [Жолудь, 2002], на типологическом и жанровом аспектах публикаций [Шахбазян, 2011], а также на анализе языка и стиля современных православных СМИ [Бакина, 2003; Ицкович, 2011]. Однако можно отметить слабую степень изученности региональных православных печатных изданий.

Материалом нашего исследования являются региональные православные печатные издания (за 2010-2016 гг.), представляющие как религиозную, так и конфессиональную журналистику: ежемесячное издание Волгоградской епархии и Царицынского православного университета преп. Сергия Радонежского «Православное слово», издание Урюпинской и Новоаннинской епархии «Епархиальные ведомости», газета «Новости Фроловского благочиния», газета «Житейское море», а также издание храма Покрова Пресвятой Богородицы х. Ветютнев «Избери жизнь».

Цель исследования - описание лингвостилистических особенностей текстов региональных православных СМИ. Публикации, размещенные в изданиях, рассматриваются как единый текстовый массив (без учета жанровых различий), что позволяет сформировать представление о православном издании в целом.

\section{Лексическая характеристика текстов региональных православных СМИ}

Анализ материала показал, что в составе лексики религиозных медиатекстов возможно выделить несколько стилистических пластов: нейтральную книжную лексику, свойственную всем функциональным стилям, и стилистически маркированную лексику, представ- 
ляющую собой тематическую группу «Православная сакрально-богослужебная лексика» (о ее выделении см.: [Королева, 2003, с. 19]). По нашим наблюдениям, стилистически маркированная лексика в текстах региональных православных изданий составляет 10-20\%. Например, в проповеди Митрополита Волгоградского и Камышинского Германа, произнесенной им на всенощной и на Божественной литургии в 2006 г. в Троицком храме СвятоДухова мужского монастыря г. Волгограда и опубликованной в газете «Православное слово», на 1259 слов приходится 220 единиц, относящихся к тематической группе «Православная сакрально-богослужебная лексика». Сакрально-богослужебная лексика в материале составляет $17,4 \%$, что подтверждает результаты исследований, проведенных О.А. Прохватиловой в рамках изучения религиозного стиля [Прохватилова, 2006, с. 22].

Тематическая группа «Православная сакрально-богослужебная лексика» в текстах региональных православных печатных изданий представлена различными частями речи: именами существительными (евхаристия, хоругвь, седмииа, причащение, воиерковление, возрождение, благодать и др.); прилагательными (божественное, Единородный, пасхальный, иерковное, благодатное, райские, православная, мирская, светотворныци, грешныц , дьявольский и др.); глаголами (проповедовать, причаститься, исповедоваться, благословить, поститься, молиться и др.) и наречиями (духовно, покаянно, благочестиво, блаженно, богоугодно и др.).

Необходимо отметить, что лексические единицы, входящие в тематическую группу «Православная сакрально-богослужебная лексика», разнообразны и могут быть разделены на семантические подгруппы.

Первая подгруппа объединяет слова, обозначающие основные понятия вероисповедания и богословские термины (вера, добро, грех, иерковное покаяние, искуситель, возрождение, благодать и др.). Например: Если мы будем печалиться о вечных благах, утерянных нами, то эта печаль произведет в нас спасительное покаяние, и мы, оплакивая свои ошибки и грехи, сможем стать достойными принятия благодати Божией (ПС) ${ }^{1}$.
Во вторую подгруппу входят слова, связанные с ритуалом, называющие элементы богослужения (литургия, всенощчная, причащение, заупокойная лития, панихида, служ$б а$ и др.). Например: Причащать младенцев надо во время каждой Литургии, на которой могут присутствовать родители, и по возможности не реже, чем каждый праздник и воскресенье (ЖМ).

Третью подгруппу составляют наименования чинов церковной иерархии (архиерей, патриарх, священник, митрополит, протоиерей и др.). Например: Но теперь и другое храмоздательство должно быть, чтобы мы думали, как говорит Святейший Патриарх Кирилл, о том, кто придет в эти храмы после нас (НФБ).

Четвертая подгруппа объединяет именования Господа и Богородицы (Сын Божсий, Дух Святой, Отеи Небесный, Светодавче, Богородииа, Господь, Спаситель, Христос и др.). Например: Да воссияет и нам грешным свет Твой присносущный молитвами Богородицы, Светодавче, слава Тебе! (ПС).

Наряду с нейтральной лексикой и стилистически маркированной, сакрально-богослужебной, можно выделить церковнославянизмы (владыка, глас и т. д.). Так, церковнославянизмы обнаруживаются в проповедях митрополита Волгоградского и Камышинского Германа, произнесенных в преддверии и во время Великого поста и опубликованных в газете «Православное слово». Отмечено их использование в примерах: Господь закрыл райские врата для того, чтобы воспитать людей в желании снова войти в рай (ПС); Ветхозаветные люди приносят Ему в жертву волов, агнцев, козлов, баранов и многое другое. Но Господь говорит им, ветхозаветным людям: Чадо, все это все равно Мое (ПС). В текстах православных печатных изданий церковнославянизмы выполняют экспрессивную функцию, создавая торжественное настроение. Кроме того, эти слова, относящиеся к высокому стилю, используются с целью воздействия на сознание читателей, их убеждения в непреложности и незыблемости религиозных истин.

Анализ материала также показал, что в текстах православных печатных изданий используется разговорная лексика: Это значит, 
что мы должны себя заставлять, понуждать, само собою ничего не будет. Никто за нас ничего делать не будет: ни патриарх, ни митрополит, ни архиерей, ни наш батюшка (НФБ). Доля таких лексем незначительна, они используются, как правило, для создания особого коммуникативного контакта с аудиторией, доверительного тона.

\section{Морфологическая характеристика текстов региональных православных СМИ}

Морфологический строй текстов православных региональных изданий имеет преимущественно именной характер. Например, в проповеди митрополита Волгоградского и Камышинского Германа, опубликованной в газете «Православное слово», на 1259 слов приходится 308 существительных и 107 прилагательных, что составляет $37 \%$ от общего количества слов в публикации; в слове митрополита Антония Сурожского об исповеди на 1060 слов приходится 225 существительных и 58 прилагательных, что составляет $27 \%$. По нашим подсчетам, состав именной лексики в текстах православных региональных СМИ может варьироваться в пределах 24-37 \% от общего объема.

Специфика морфологического строя текстов православных газет проявляется в функционировании глагольной лексики. Так, стилистическим маркером является использование настоящего времени богословского обобщения [Лихачев, 1979, с. 84]. Например: И это надо помнить, потому что мы исповедуемся не священнику, и не он является нашим судьей. Я бы сказал больше: даже Христос не является в этот момент нашим Судьей, а является сострадающим нашим Спасителем (ЖМ); Апостол Павел нас учит, что печаль по Богу покаяние во спасение соделывает. А ведь бывает и печаль мира сего: всякие досады, злоба, суетное желание иметь жизненные блага - а они уходят от нас, и тогда печаль обуревает, вернее, помрачает наше сердие; такая печаль смерть соделывает (ПС). В данных примерах настоящее богословского обобщения выражает «вечный» смысл и подчеркивает, что все, о чем говорится, имеет вневре- менной характер. В публикациях православных СМИ часто говорится о пороках и добродетелях, свойственных людям на протяжении всей истории человечества. С помощью формы настоящего богословского обобщения вводятся высказывания наиболее авторитетных духовных лиц, усиливается актуальность и современность содержания речи.

Особенностью, характеризующей тексты православных региональных СМИ, является использование глаголов в повелительном наклонении (синтетические и аналитические формы): Так вот перестанем печалиться о всяких благах, которые нам хотелось бы иметь, но которых у нас нет (ПС); Так вот, дорогие мои братья и сестры, постараемся мы помнить о том, что нас, блуждающих по грешным путям грешного мира сего, Господь ждет с покаянием - когда мы к Нему обратимся (ПС). Из приведенных выше примеров видно, что использование аналитических форм императива сочетается с «мы»-формами. Такие конструкции имеют значение побуждения к совместному действию (инклюзивный императив), которое позволяет священнослужителю подчеркнуть единство с аудиторией, включенность адресанта речи и ее адресатов в совместную деятельность. При этом необходимо отметить, что императивные формы имеют некатегоричный характер: они выполняют функцию совета, увещевания или содержат призыв к выполнению определенного действия.

\section{Синтаксическая характеристика текстов региональных православных СМИ}

Синтаксической особенностью текстов региональных печатных изданий является широкое использование двусоставных распространенных предложений, вопросительных конструкций, вопросно-ответных единств, позиционно-лексических повторов, однородных членов предложения. Так, эмоциональность высказываний передается при помощи вопросительных предложений, которые помогают вовлечь читателя в диалог, сподвигнуть его к соразмышлению: Он должен поставить перед собой вопрос: если моя жена, мои дети, самый мой близкий друг, мои сослужсивиы знали бы 
обо мне то или другое, было бы мне стылно или нет? Если стыдно - исповедуй. Если то или другое было бы мне стылно открыть Богу, Который и без того это знает, но от Которого я стараюсь это спрятать, мне было бы страшно? (ЖМ). Приведенный пример представляет собой вопросно-ответное единство - средство, помогающее воздействовать на эмоции читателя, вызвать у адресата душевный отклик, создать эффект сопричастности, а также актуализировать важную для него информацию.

Стилистическим средством экспрессивного синтаксиса, отмеченным в текстах православных региональных изданий, является позиционно-лексический повтор - разновидность повтора, которая предполагает однородность повторяемых синтаксических позиций и тождество их лексического наполнения [СТилистический энциклопедический словарь..., 2006, с. 479]. Например: Страх Господень чист и пребывает вовек. Страх Божий самая большая добродетель для каждого из нас. Страх Божсий будет в том, если мы будем бояться потерять Божию любовь, бояться оскорбить Бога, бояться сделать что-нибудь вопреки Его воле, чтонибудь подлое, гнусное, пакостное. Страх Божий спасительный и вовеки сохранит верующего человека (ПС). В приведенном контексте повтор реализует акцентирующую функцию и является средством экспрессивного выделения важной для Православия идеи: страх Божий представляет собой Христианскую добродетель, основанную на благоговении перед Господом и почитании гнева Отца Небесного.

В текстах региональных православных СМИ можно отметить широкое употребление однородных членов предложения: Упорядочиваются мысли, чувства, желания, всякая чепуха уходит из сознания, и Господь по праву занимает Свое место державного присутствия в нашем сознании, в нашей душе, в нашем сердце (ПС). В данном примере использованы однородные подлежащие, а также однородные обстоятельства - позиционно-лексический повтор, усиливающий патетическую позицию автора, акцентирующий важные смыслы изложения, создающий определенный ритм, свойственный духовной речи.
Важным средством экспрессивного синтаксиса в текстах религиозных печатных изданий является инверсия. Наиболее частотной инверсивной конструкцией становится постпозиция согласованного определения, исторически обусловленная влиянием архаических синтаксических конструкций, которые воспроизводятся в духовной речи: иарствие Небесное, Отеи Небесный, храм Божий, жизнь вечная, душа человеческая и т. д. Инверсивные конструкции в предложениях используются, по нашим наблюдениям, в семантически наиболее значимых сочетаниях, которые определяют самые важные православные понятия.

\section{Стилистическая характеристика текстов региональных православных СМИ}

Особенностью текстов православных печатных СМИ является широкое использование стилистических фигур, усиливающих выразительность речи. Например: Дело в том, что мы с вами имеем от Бога надежду на вечное благо. Вечное благо верующим в Него Господь обещал дать за верность, за труды праведные, за исповедание веры в истинного Бога (ПС). В приведенном примере отмечается употребление анадиплозиса - приема, заключающегося в повторе завершающего словосочетания в начале следующей фразы.

Для противопоставления мирского Божественному, грешного благодетельному в текстах часто применяются развернутые антитезы: вразумленные святыми словами о вечной жнзни во исправление своей временной жсизни (ПС); Так вот, из блудных детей надо через покаяние снова стать достойными чадами Божиими с надеждой получить жизнь вечную (ПС); время Великого поста как раз и способствует тому, чтобы подумать обо всем и постараться отмести из жсизни всякую суету, сосредоточиться на святых словах, на святых молитвах, обращенных к нашему Богу и Спасителю, и открыть Ему свое сердие (ПС).

Для усиления выразительного эффекта в материалах православных изданий используется градация: Желаю, чтобы это было вам в утешение, очищение, спасение и в жизнь 
вечную (ПС); Благодать Причащения Тела и Крови Господа необычайна: она возвращает, исцеляет и укрепляет ребенка духовно и физически (ЖМ).

Стилистические фигуры, обладающие высокой степенью выразительности и создающие определенный ритм изложения, появляются в семантически наиболее значимых фрагментах.

\section{Выводы}

В текстах региональных православных печатных изданий особенности лексического, морфологического и синтаксического строя обусловлены традициями духовной речи. В составе лексики выделяются стилистически маркированные лексемы тематической группы «Православная сакрально-богослужебная лексика» и церковнославянизмы. Морфологический строй текстов православных изданий имеет преимущественно именной характер. Глаголы представлены формами настоящего времени, выражающими значение богословского обобщения, и формами повелительного наклонения. Синтаксические особенности создаются вопросительными конструкциями, вопросно-ответными единствами, позиционнолексическими повторами, однородными членами предложения, инверсией. Использование языковых средств, характерных для духовной речи, объясняется стремлением авторов воздействовать на сознание читателей с целью их убеждения в непреложности и незыблемости религиозных истин.

Широкое применение стилистических фигур, обладающих высокой степенью выразительности, акцентирует семантически значимые фрагменты, а также создает особый ритм духовной речи.

\section{ПРИМЕЧАНИЕ}

${ }^{1}$ В статье приводятся примеры из следующих источников:

ЖM - Житейское море : газета Волжского благочиния, по благословению Митрополита Волгоградского и Камышинского Германа. - 2012. - № 3 (38). 8 полос. - ежемес. - 998 экз.;

НФБ - Новости Фроловского благочиния : газета Фроловского благочиния / учредитель храм
Покрова Пресвятой Богородицы. - 2012. - № 5 (8). 4 полосы. - ежемес. - 999 экз.;

ПС-Православное слово : ежемесячное издание Волгоградской епархии и Царицынского православного университета преп. Сергия Радонежского / учредитель Волгоградская епархия Русской Православной Церкви. - 2011. - № 3 (221). - 16 полос. - ежемес. -6000 экз.

\section{СПИСОК ЛИТЕРАТУРЫ}

Бакина О. В., 2003. Современная православная журналистика России. Киров : КФ МГЭИ. 221 с.

Жолудь Р. В., 2002. Начало православной публицистики: Библия, апологеты, византийцы. Воронеж : Воронеж. гос. ун-т. 192 с.

Ицкович Т. В., 2011. Язык и стиль современных православных СМИ (на материале СМИ Екатеринбургской епархии) // Меди@альманах. № 4 (45). С. $44-48$.

Королева И. А., 2003. Православная сакрально-богослужебная лексика в современном русском языке и в художественном тексте : дис. ... канд. филол. наук / Королева Илона Анатольевна. Волгоград. $186 \mathrm{c.}$

Лихачев Д. С., 1979. Поэтика древнерусской литературы. М. : Наука. 360 с.

Прохватилова О. А., 2006. Экстралингвистические параметры и языковые характеристики религиозного стиля // Вестник Волгоградского государственного университета. Серия 2, Языкознание. № 5. С. 19-26.

Стилистический энциклопедический словарь русского языка, 2006. Под ред. М. Н. Кожиной. М. : Флинта : Наука. 696 с.

Шахбазян М. А., 2011. Церковная проповедь как парадигма русской религиозно-философской публицистики // Вестник Адыгейского государственного университета. Серия «Филология и искусствоведение». Вып. 1. С. 58-63.

\section{REFERENCES}

Bakina O.V., 2003. Modern Orthodox journalism in Russia. Kirov, KB MGEU Publ. 221 p.

Zholud R.V., 2002. The Beginning of Orthodox journalism: the Bible, the apologists, the Byzantines. Voronezh, Voronezh State University Publ. 192 p.

Itskovich T.V., 2011. Language and style of contemporary Orthodox media (based on materials of Ekaterinburg's diocese mass media). Medi@almanakh [Medi@almanah Journal], no. 4(45), pp. 44-48. 
E.A. Овечкина. Тексты региональных православных СМИ в лингвостилистическом аспекте

Koroleva I.A., 2003. The Orthodox sacred-divineservice vocabulary in the modern Russian language and in the literary text. Dissertation for Candidate of Sciences in Philology Degree. Volgograd. $186 \mathrm{p}$.

Likhachev D.S., 1979. Poetics of old Russian literature. Moscow, Nauka Publ. 360 p.

Prokhvatilova O.A., 2006. Extralinguistic parameters and linguistic characteristics of the religious style. Vestnik Volgogradskogo gosudarstvennogo universiteta. Seriya 2, Yazykoznanie [Science
Journal of Volgograd State University. Linguistics], no. 5, pp. 19-26.

Kozhina M.N., ed. 2006. Stylistic encyclopedic dictionary of the Russian language. Moscow, Flinta; Nauka Publ. 696 p.

Shakhbazyan M.A., 2011. The Church sermon as a paradigm of Russian religious-philosophical publicism. Vestnik Adygeyskogo gosudarstvennogo universiteta. Seriya «Filologiya $i$ iskusstvovedenie» [The Bulletin of the Adyghe State University. Series "Philology and the Arts"], vol. 1, pp. 58-63.

\section{Information about the Author}

Elena A. Ovechkina, Candidate of Sciences (Philology), Senior Lecturer, Department of Journalism and Media Communications, Volgograd State University, Prosp. Universitetsky, 100, 400062 Volgograd, Russia, ea_ovechkina@volsu.ru, stilvolsu@mail.ru,https://orcid.org/0000-0002-9316-4383

\section{Информация об авторе}

Елена Алексеевна Овечкина, кандидат филологических наук, старший преподаватель кафедры журналистики и медиакоммуникаций, Волгоградский государственный университет, просп. Университетский, 100, 400062 г. Волгоград, Россия, ea_ovechkina@volsu.ru, stilvolsu@mail.ru, https://orcid.org/0000-0002-9316-4383 